\title{
A Different Clinical Type of OSAS: REM-Related OSAS
}

\author{
Handan İnönü Köseoğlu ${ }^{1}$, Asiye Kanbay², Osman Demir ${ }^{3}$
}

${ }^{1}$ Department of Chest Diseases, Gaziosmanpaşa University Faculty of Medicine, Tokat

${ }^{2}$ Department of Chest Diseases, Medeniyet University Faculty of Medicine, İstanbul

${ }^{3}$ Department of Biostatistics and Medical Informatics, Gaziosmanpaşa University Faculty of Medicine, Tokat

\begin{abstract}
Objective: Rapid eye movement (REM) is an entity in which the collapsibility of upper respiratory tract increases. Different opinions have been proposed with regard to the definition of REM-related obstructive sleep apnea syndrome (OSAS). Some authors consider REM-related OSAS as the first presentation, and others consider it as a different clinical type of OSAS. We aimed to compare the clinical and polysomnographic findings of REM-related and non-REM-related OSAS patients to test whether REM-related OSAS is a different clinical type OSAS or the manifestation of early stage or the onset of OSAS.
\end{abstract}

Methods: The study had a retrospective design. Patients with an initial diagnosis of sleep-related breathing disorders were later diagnosed to have OSAS based on an apnea-hypopnea index (AHI) of $\geq 5$ and were divided into the following two groups: patients with AHINREM of $<5$ and AHIREM/AHINREM of > 2 whose REM recordings were obtained for at least 30 min were defined as having "REM-related OSAS," and those who did not meet this description were defined as having "non-REM-related OSAS."

Results: A total of 329 patients with a mean age of $51 \pm 10$ years were included in the study. Thirty-five (10.6\%) patients with OSAS were REM-related and 294 (89.4\%) were non-REM-related. Age, body mass index, smoking status, and concomitant diseases were comparable between groups ( $p>0.05)$. In REM-related patients, AHI was lower, REM duration was longer, and mean oxygen saturations were comparatively higher $(p<0.05)$.

Conclusion: Similarities between groups in age, body mass index, and concomitant disease suggest that REM-related OSAS is a different clinical type of OSAS, rather than the early phase of OSAS.

Keywords: Obstructive sleep apnea syndrome, REM dependency, REM-related obstructive sleep apnea syndrome

Received Date: 21.03.2015 Accepted Date: 09.07.2015

Address for correspondence Handan İnönü Köseoğlu

E-mail: handaninonu@gmail.com

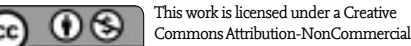
Commons Attribution-NonCommercia 4.0 International License.

DOI: $10.5152 /$ ejp.2015.78941

-Available online at www.eurasianjpulmonol.com

\section{INTRODUCTION}

Obstructive sleep apnea syndrome (OSAS) is characterized by repetitive episodes of complete or partial upper airway obstruction during sleep. Repetitive episodes of airway obstruction lead to increasing respiratory efforts, intermittent arterial oxygen desaturation, systemic and pulmonary arterial blood pressure surges, and sleep disorders (1). We sleep occupies for nearly one-third of our life, and it is an essential and vital part of our life. Although it is perceived as a resting period for the body, during some stages of sleep, the brain and many bodily systems are extremely active. Sleep is evaluated in two stages as rapid eye movement (REM) and non-REM. The REM stage is named after REM during this phase. This stage is classified as tonic and phasic REM. During this stage, brain activity with mixed frequency, erection, thermoregulation loss, muscle twitching, cardiorespiratory disorder, respiratory control impairment, and irregular ventilation occur $(2,3)$. During REM, pharyngeal muscle activity decreases, and upper airway collapsibility increases as a result of the absence of excitatory, noradrenergic, and serotonergic stimuli in upper airway motor neurons (4). Therefore, in patients with OSAS during REM sleep, the number and duration of obstructive respiratory events increase with resultant serious oxygen desaturation. REM as a specific respiratory disorder was first described in 1996. From that day on, different expressions and diagnostic criteria have been used for the presence and definition of REM-related OSAS. Some authors have accepted this disorder as not a separate entity, but rather a component of an OSAS spectrum, and they indicated REM-related OSAS as an essentially early (baseline presentation) phase of classical OSAS, while others defined it as a different clinical type of $\operatorname{OSAS}(3,5,6)$. In the present study, we aimed to compare the clinical and polysomnographic findings of REM-related and non-REM-related OSAS patients to test whether REM-related OSAS is a different clinical type OSAS or the manifestation of early stage or the onset of OSAS. 


\section{METHODS}

\section{Subjects and Study Design}

The medical records of patients over the age of 18 years who underwent polysomnography (PSG) between January 2011 and January 2014 with an initial diagnosis of sleep-related breathing disorder were retrospectively reviewed. Among them, those with an apnea-hypopnea index $(\mathrm{AHI})$ of $\geq 5$ and a diagnosis of OSAS were included in the study. Data related to demographic characteristics, sleep patterns, medical history, medication use, and habits were retrieved using a standardized questionnaire survey applied before the study. For the evaluation of sleepiness during the day, Epworth Sleepiness Scale (ESS) was used (7). Based on their $\mathrm{AHI}$, the patients were categorized in the mild $(\mathrm{AHI}=5-15)$, moderate $(\mathrm{AHI}=15-30)$, and severe OSAS $(\mathrm{AHI}>30)$ groups according to the American Academy of Sleep Medicine (AASM) Task Force criteria (8). Respiratory events observed during each stage of sleep were determined, and AHI for REM $\left(\mathrm{AHI}_{\mathrm{REM}}\right)$ and non-REM $\left(\mathrm{AHI}_{\mathrm{NREM}}\right)$ were calculated. Similarly, $\mathrm{AHI}$ while the patient was sleeping in the supine $\left(\mathrm{AHI}_{\text {SUPINE}}\right)$ and other positions $\left(\mathrm{AHI}_{\text {NON-SUPINE}}\right)$ were also calculated. The study population was divided into two groups: those with $\mathrm{AHI}_{\text {NREM }}$ of $<5$ and $\mathrm{AHI} \mathrm{REM}_{\text {R }} / \mathrm{AHI}_{\text {NREM }}$ of $>2$ and those with OSAS whose REM sleep data were recorded for at least 30 min were classified as having "REM-related OSAS," and those who did meet the criteria of this definition were classified as having "non-REM-related OSAS." Patients with central sleep apnea syndrome, upper airway resistant syndrome, narcolepsy, and movement disorders were excluded from the study. We also excluded patients using drugs effective for REM sleep, including benzodiazepine derivatives and narcotics. This study was conducted in accordance with the tenets of the Declaration of Helsinki, and written informed consent was obtained from all subjects. The study protocol was reviewed and approved by the local institutional review board and ethics committee of Gaziosmanpaşa University.

\section{Polysomnographic Evaluation}

Overnight PSG was performed in all patients using a 55-channel polysomnograph (Alice ${ }^{\circledR}$ Sleepware, Philips Respironics, PA, USA)

Table 1. Demographic and clinical features of the study population

\begin{tabular}{|c|c|c|c|}
\hline & $\begin{array}{l}\text { REM-Related } \\
\text { OSAS }(n=35)\end{array}$ & $\begin{array}{l}\text { Non-REM-Related } \\
\text { OSAS }(n=294)\end{array}$ & p \\
\hline Age (years)* & $52 \pm 10$ & $51 \pm 10$ & \multirow{3}{*}{$\begin{array}{l}0.855 \\
0.007\end{array}$} \\
\hline Gender, Male n (\%) & $18(51)$ & $219(74)$ & \\
\hline Female $\mathrm{n}(\%)$ & $17(49)$ & $75(26)$ & \\
\hline BMI $\left(\mathrm{kg} / \mathrm{m}^{2}\right)^{*}$ & $32.05 \pm 4.48$ & $33.88 \pm 7.08$ & 0.137 \\
\hline ESS* & $11.9 \pm 4.1$ & $11.6 \pm 4.3$ & 0.75 \\
\hline Smoking, n (\%) & $6(17.1)$ & $63(21.4)$ & 0.712 \\
\hline $\mathrm{CVD}^{\&}, \mathrm{n}(\%)$ & $1(2.9)$ & $4(1.4)$ & 0.432 \\
\hline DM, n (\%) & $6(17.1)$ & 55 (18.7) & 0.999 \\
\hline HT, n (\%) & $10(28.6)$ & $100(34)$ & 0.649 \\
\hline $\mathrm{CVD}^{\#}, \mathrm{n}(\%)$ & $7(20.6)$ & $60(20.6)$ & 0.999 \\
\hline
\end{tabular}

* Mean \pm standard deviation

BMI: Body mass index; CVD\&: cerebrovascular diseases; CVD": cardiovascular disease; DM: diabetes mellitus; ESS: Epworth sleepiness score; HT: hypertension; OSAS: Obstructive sleep apnea syndrome and included the following variables: electrooculograms (two channels), electroencephalograms (four channels), electromyograms of the submental muscles (one channel) and anterior tibialis muscle of both legs (two channels), electrocardiograms, airflow measurements (with oronasal thermistor and nasal cannula pressure transducer), body position sensor discerning changes in body position during sleep, and a snore sensor for the detection of snoring vibrations. Respiratory efforts of chest and abdominal muscles (two channels) were recorded using piezoelectric belts and arterial oxyhemoglobin saturation $\left(\mathrm{SaO}_{2}\right.$ : one channel) by pulse oximetry with a finger probe. The recordings were scored according to the standard criteria of AASM. Apnea was defined as $\geq 90 \%$ decrease in the air flow amplitude persisting for at least $10 \mathrm{~s}$ relative to the baseline amplitude. Hypopnea was defined as $\geq 50 \%$ decrease in air flow amplitude relative to the baseline values associated with $a \geq 3 \%$ oxygen desaturation or arousal from sleep, all sustaining for at least 10 $s$ (9). AHI was calculated as the number of apneic plus hypopneic episodes per hour of sleep. Patients with $\mathrm{AHI}$ of $\geq 5$ events/h were diagnosed as having OSAS. Oxygen desaturation index was defined as the total number of measurements of oxyhemoglobin desaturation of $\geq 4 \%$ within $\geq 10 \mathrm{~s}-<3 \mathrm{~min}$ from the baseline divided by the total sleep time.

\section{Statistical Analysis}

For the evaluation of categorical variables, chi-square test was used. Categorical variables were expressed as numbers and percentages. For categorical variables, histograms were employed. To test the normality of distribution of variables, Shapiro-Wilks normality test was utilized. For intergroup comparisons of continuous variables, independent samples $t$ test or Mann-Whitney $U$ test was used. In cases where parametric methods were used, continuous measurements were expressed as mean \pm standard deviation, if nonparametric methods were used, variables were indicated as median and 25 and 75 percentiles. A multivariate logistic regression model was implemented to determine the relationship among selected variables and REM dependence. Variables whose significance is under 0.10 were added to the logistic regression model. $p<0.05$ was considered as the level of statistical significance. Calculations were performed using a pre-prepared statistical software program (IBM SPSS Statistics 19, SPSS Inc., IBM Co., Somers, New York, USA).

\section{RESULTS}

A total of 329 patients with a mean age of $51 \pm 10$ years were evaluated. The patients were included in the REM-related $(n=35 ; 10.6 \%)$ and non-REM-related $(n=294 ; 89.4 \%)$ groups. The groups did not differ with regard to comorbidities, such as cerebrovascular disease, diabetes, hypertension, cardiovascular disease (this group included arrhytmia, congestive heart failure, and coronary artery disease); mean age; body mass index (BMI); ESS; and smoking history ( $p>0.05)$. The distribution of gender differed between groups (REM-related OSAS, male $51 \%$ and female $49 \%$; non-REM-related, male $71 \%$ and female $26 \%, p=0.007$ ) (Table 1). During PSG evaluation, AHI was lower, REM and NREM stage 3 sleep duration were longer, NREM stage 1 and 2 duration were shorter, and mean and minimum oxygen saturation values were higher in patients with REM-related OSAS with significant differences between groups $(p<0.05$ ) (Table 2). Also, $46 \%$ of REM-related OSAS patients had a position dependence (in the other group, this rate was only $19.7 \%$ ) with a significant intergroup difference $(p=0.001)$. In REM-related patients, mild $(91.4 \%)$ and moderate $(8.6 \%)$ degrees of OSAS were detected. This group did not contain 


\begin{tabular}{|c|c|c|c|}
\hline & $\begin{array}{l}\text { REM-Related } \\
\text { OSAS }(n=35)\end{array}$ & $\begin{array}{l}\text { Non-REM-Related } \\
\text { OSAS }(n=294)\end{array}$ & p \\
\hline Stage $1^{\#}$ & $5.10(2.60-10.70)$ & $8.90(4.80-15.20)$ & 0.001 \\
\hline Stage $2^{\#}$ & $40(34.60-45.40)$ & $46.80(38-53.70)$ & $<0.001$ \\
\hline Stage $3^{\#}$ & $33.30(27-38.30)$ & $27(18.40-34.20)$ & $<0.001$ \\
\hline REM \#,* & $19.96 \pm 5.08$ & $14.75 \pm 6.68$ & $<0.001$ \\
\hline SE $(\%)^{*}$ & $84.03 \pm 10.01$ & $81.56 \pm 10.71$ & 0.195 \\
\hline $\mathrm{AHI}$ & $8.40(6.30-11.10)$ & $38.80(22.90-60.70)$ & $<0.001$ \\
\hline Desaturation (\%) & $0.40(0.10-1.40)$ & $4.10(0.40-22.80)$ & $<0.001$ \\
\hline ODI & $8.60(5-11.70)$ & $31.35(18.60-57.40)$ & $<0.001$ \\
\hline $\begin{array}{l}\text { Wake } \mathrm{O}_{2} \\
\text { saturation (\%) }\end{array}$ & $96(94-96)$ & $95(93-96)$ & 0.001 \\
\hline $\begin{array}{l}\text { Average } \mathrm{O}_{2} \\
\text { saturation (\%) }\end{array}$ & 95 (94-96) & $93(91-95)$ & $<0.001$ \\
\hline $\begin{array}{l}\text { Minimum } \mathrm{O}_{2} \\
\text { saturation (\%) }\end{array}$ & $85(81-88)$ & $80(69-86)$ & $<0.001$ \\
\hline Severity of OSAS & & & \\
\hline $\begin{array}{l}\text { Mild, } \mathrm{n}(\%) \\
\text { Moderate, } \mathrm{n}(\%) \\
\text { Severe, } \mathrm{n}(\%)\end{array}$ & $\begin{array}{c}32(91.4) \\
3(8.6) \\
0(0)\end{array}$ & $\begin{array}{c}43(14.6) \\
62(21.1) \\
189(64.39)\end{array}$ & $<0.001$ \\
\hline $\begin{array}{l}\text { Position } \\
\text { dependence, n (\%) }\end{array}$ & $16(45.7)$ & $58(19.7)$ & 0.001 \\
\hline $\mathrm{AHI}_{\text {SUPINE }}$ & $\begin{array}{c}18.75(13.60-25.00) \\
19.09 \pm 7.11\end{array}$ & $\begin{array}{c}32.20(21.10-57.30) \\
40.66 \pm 24.43\end{array}$ & 0.001 \\
\hline $\mathrm{AHI}_{\text {NONSUPINE }}$ & $\begin{array}{c}1.40(0.00-2.10) \\
1.82 \pm 1.95\end{array}$ & $\begin{array}{c}1.90(0.70-3.30) \\
2.12 \pm 1.64\end{array}$ & 0.357 \\
\hline \multicolumn{4}{|c|}{$\begin{array}{l}\text { * Mean } \pm \text { standard deviation } \\
\text { \# Sleep stages are given as } \% \text { of total sleep time } \\
\text { AHI: Apnea -hypopnea index; Desaturation } \% \text { : Sleep time of } \mathrm{SpO}_{2}<90 \% \text {; } \\
\text { ODI: oxygen desaturation index; OSAS: Obstructive sleep apnea syn- } \\
\text { drome; REM: rapid eye movement; SE: sleep efficiency }\end{array}$} \\
\hline
\end{tabular}

patients with severe OSAS. The severity of OSAS differed significantly between groups (Table 2, Figure 1). Demographic findings and polysomnographic features of both groups are presented in Table 3 and Table 4.

Potential determinants for REM dependence were further investigated in a univariate screening procedure. Subsequently, all parameters related to REM dependence with a significance level below 0.1 were introduced in a stepwise multiple regression analysis. The final regression model included age, gender, $\mathrm{BMI}$, position dependence, $\mathrm{AHI}$, desaturation $\%$, average $\mathrm{O}_{2}$ saturation, minimum $\mathrm{O}_{2}$ saturation. The independent predictors of REM dependence were AHI and minimum $\mathrm{O}_{2}$ saturation in patients with OSAS. Positional OSAS was not a significant factor for REM dependence (Table 5).

\section{DISCUSSION}

The most striking outcome of our study is that severe OSAS patients were not encountered in the REM-related OSAS group, whereas the frequency of comorbidities such as cerebrovascular disease, diabetes, hypertension, and cardiovascular disease were similar to those in the non-REM-related group. Another important result of this study was that the mean age and BMI of both groups were comparable.

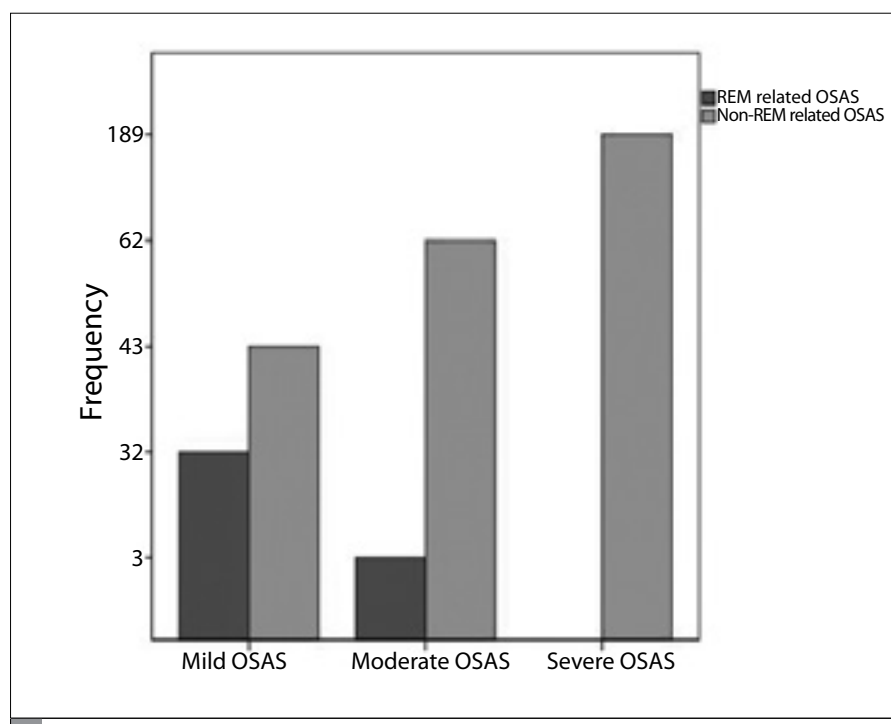

Figure 1. The distribution of patients according to the severity of OSAS

Table 3. Demographic findings of both groups

\begin{tabular}{|c|c|}
\hline & $\begin{array}{l}\text { REM-Related and Non-REM- } \\
\text { Related OSAS }(n=329)\end{array}$ \\
\hline Age (years)* & $51.27 \pm 10.40$ \\
\hline Gender, Male n (\%) & $237(72)$ \\
\hline Female n (\%) & $92(28)$ \\
\hline BMI $\left(\mathrm{kg} / \mathrm{m}^{2}\right)^{*}$ & $33.69 \pm 6.87$ \\
\hline $\mathrm{ESS}^{*}$ & $11.98 \pm 4.9$ \\
\hline Smoking, n (\%) & $69(21)$ \\
\hline $\mathrm{CVD}^{\&}, \mathrm{n}(\%)$ & $5(1.5)$ \\
\hline DM, n (\%) & $61(18.5)$ \\
\hline HT, n (\%) & $110(33.4)$ \\
\hline $\mathrm{CVD}^{\#}, \mathrm{n}(\%)$ & $67(20.6)$ \\
\hline \multicolumn{2}{|c|}{$\begin{array}{l}\text { * Mean } \pm \text { standard deviation } \\
\text { BMI: Body mass index; CVD\&: cerebrovascular diseases; CVD": cardiovas- } \\
\text { cular disease; DM: Diabetes mellitus; ESS: Epworth sleepiness score; HT: } \\
\text { hypertension; OSAS: Obstructive sleep apnea syndrome }\end{array}$} \\
\hline
\end{tabular}

REM as a specific respiratory disorder was first described by Kass et al. (10) in 1996 as a cause of excessive daytime sleepiness. In a study where 34 patients with clinically suspect OSAS with respiratory disturbance index (RDI) of $<10$ were evaluated, in a substantial percentage of patients who described excessive daytime sleepiness, the presence of REM-related OSAS was demonstrated. From that day on, different expressions and diagnostic criteria have been used for the presence and definition of REM-related OSAS. Some authors accepted this disorder as not being a separate entity, but rather a component of an OSAS spectrum, and they indicated REM-related OSAS as an essentially early (baseline presentation) phase of classical OSAS $(3,5,6)$. According to these authors, with aging and gaining weight (in the advanced stage of the disease in particular) of the patients, respiratory events seen only during the REM stage at the onset of 
REM-related OSAS will be also observed during the non-REM stage. Thus, patients will enter into the advanced (severe) stage of OSAS, and respiratory pathologies will be seen both during the REM and non-REM stages of the disease.

The prevalence of REM-related OSAS varies within a wide spectrum (10-36\%) $(6,11-13)$. These highly variable outcomes stem from differences in criteria used for the definition of REM-related OSAS. It has been emphasized that $A I_{\text {REM }}$ should be at least 2 times higher than $\mathrm{AHI}_{\mathrm{NREM}}$; however different values have been reported for $\mathrm{AHI}_{\mathrm{N}-}$

Table 4. Polysomnographic features of both groups

\begin{tabular}{|c|c|}
\hline & $\begin{array}{l}\text { REM-Related and Non- } \\
\text { REM-Related OSAS }(n=329)\end{array}$ \\
\hline Stage $1^{\#}$ & $11.05 \pm 9.13$ \\
\hline Stage $2^{\#}$ & $46.50 \pm 12.60$ \\
\hline Stage $3^{\#}$ & $27.12 \pm 11.27$ \\
\hline REM \#, & $15.31 \pm 6.71$ \\
\hline SE $(\%)^{*}$ & $81.83 \pm 10.65$ \\
\hline $\mathrm{AHI}$ & $40.54 \pm 28.67$ \\
\hline Desaturation (\%) & $15.35 \pm 25.12$ \\
\hline ODI & $38.07 \pm 30.93$ \\
\hline Wake $\mathrm{O}_{2}$ saturation (\%) & $93.96 \pm 3.17$ \\
\hline Average $\mathrm{O}_{2}$ saturation(\%) & $92.06 \pm 4.78$ \\
\hline Minimum $\mathrm{O}_{2}$ saturation $(\%)$ & $75.94 \pm 13.97$ \\
\hline \multicolumn{2}{|l|}{ Severity of OSAS } \\
\hline Mild, n (\%) & $75(22.8)$ \\
\hline Moderate, n (\%) & $65(19.8)$ \\
\hline Severe, n (\%) & $189(57.4)$ \\
\hline Position dependence, n (\%) & $74(22.5)$ \\
\hline \multicolumn{2}{|c|}{$\begin{array}{l}\text { * Mean } \pm \text { standard deviation } \\
\text { \# Sleep stages are given as \% of total sleep time } \\
\text { AHI: Apnea -hypopnea index; Desaturation \%: Sleep time of } \mathrm{SpO}_{2}<90 \% \text {; } \\
\text { ODI: Oxygen desaturation index; REM: rapid eye movement; SE: sleep } \\
\text { efficiency }\end{array}$} \\
\hline
\end{tabular}

REM $\left(\mathrm{AHI}_{\text {NREM }}<5\right.$ or $\left.<10\right)(11,14,15)$. In studies that used diagnostic criteria similar to ours, $\mathrm{AHI}$ have ranged between $10 \%$ and $13 \%$ (16, 17). Another important diagnostic criterion is an adequate duration of REM sleep. With regard to the amount of adequate sleeping times, there are different opinions. REM sleep lasting for at least 15 or 30 $\mathrm{min}$ is deemed to be necessary. Polysomnographic examinations performed in sleep laboratories of Chicago and Johns Hopkins University demonstrated that in $75 \%$ of patients who visited sleep disorder centers and underwent full-night PSG, REM sleep lasted for at least $30 \mathrm{~min}$ (18).

Because of differences in the definition criteria, in cases with REM-related OSAS, clinical characteristics also demonstrate differences. In many studies, a higher incidence of REM-related OSAS has been reported in women $(3,6,12,13,19,20)$. Higher $A \mathrm{HI}_{\text {REM }}$ relative to $A \mathrm{HI}_{\text {NREM }}$ in women suggest the protection of women from respiratory events in NREM sleep. This protection has a physiological basis. During wakefulness, the activity of the genioglossus muscle is more potent when compared with men (21). During NREM sleep, the resistance of the upper respiratory tract and collapsibility is lower in women (22). The respiratory center-stimulating effect of progesterone together with its protective effect against upper respiratory tract obstruction by increasing the tonus of the pharyngeal dilator muscle account for the protection of women against respiratory events during NREM sleep (23). On the other hand, during REM, a decrease in ventilatory response, pharyngeal muscle tone, and as a probability, reduced protective effect of sex hormones tend to increase the constriction of the upper respiratory tract (18). The abovementioned mechanisms may explain the reason for the higher incidence of REM-related OSAS in women; however, some outcomes suggest comparable incidence rates between men and women $(24,25)$. In our study, in REM-related and non-related groups, female patients constituted $49 \%$ and $26 \%$ of the patient population, respectively. Even though an increased number of female patients was detected in the REM-related OSAS group than in the other group, in the REM-related OSAS group, male predominance $(51 \%)$ prevailed. Another point that demonstrated intergroup difference is that REM-related OSAS patients are relatively younger. The authors attributed the younger patient population in the REM-related OSAS group to its being the early phase presentation of classical OSAS. On the other hand, in various studies, authors could not detect any difference between the mean ages of patients with or without REM-related OSAS $(3,11,24)$. Also, in our study, the mean ages of patients in both groups were found to be similar.

Table 5. Logistic regression analysis for REM-dependent OSAS

\begin{tabular}{|c|c|c|c|c|c|}
\hline Variables & $\beta$ & S.E. & p & Odds ratio & Confidence interval 95\% \\
\hline Gender & 0.668 & 0.540 & 0.216 & 1.951 & $0.676-5.626$ \\
\hline BMI & 0.061 & 0.051 & 0.230 & 1.063 & $0.962-1.175$ \\
\hline Positional OSAS & 0.033 & 0.479 & 0.944 & 1.034 & $0.404-2.644$ \\
\hline Average $\mathrm{O}_{2}$ saturation & -0.149 & 0.200 & 0.456 & 0.861 & $0.582-1.275$ \\
\hline Minimum $\mathrm{O}_{2}$ saturation & -0.127 & 0.055 & 0.022 & 0.881 & $0.790-0.982$ \\
\hline
\end{tabular}

AHI: Apnea-hypopnea index; BMI: Body mass index; Desaturation \%: Sleep time of $\mathrm{SpO}_{2}<90 \%$, OSAS: Obstructive sleep apnea syndrome; S.E.: Standard error 
Obesity is an important risk factor in the development of OSAS (26). In the development of REM-related OSAS, the role of obesity is not clear. In a study population of 419 patients, logistic regression analysis was performed to predict REM-related OSAS. In total, 138 patients with REM-related OSAS were detected, and higher BMI was concluded to be an independent variable. The use of only $\mathrm{AHI}_{\mathrm{REM}}>2$ $\times \mathrm{AHI}_{\text {NREM }}$ criterion to define REM-related OSAS, and the detection of increased incidence (32.9\%) of REM-related patients in that study have been criticized (3). Lakadamyalı et al. (24) found similar BMls between REM-related and non-related groups, and in the former group, a higher number of female participants were obese compared with male participants. In our study, the mean BMI values did not differ between groups regarding the gender of the patients.

REM-related OSAS was first described in 1996 as a cause of excessive daytime sleepiness, and with subsequent studies on REM-related OSAS, higher ESSs were more frequently detected in patients with REM-related OSAS. However, some authors obtained similar incidence rates of sleepiness in patients with non-REM-related OSAS $(3,24,25)$. Additionally, in our study, the mean ESSs were similar between both groups.

Patients with REM-related OSAS are generally in mild-moderate OSAS groups, and this group rarely contains severe patients $(3,6,11$ $13,20,24,25,27)$. Also, in our study, the REM-related OSAS group consisted of only patients with mild and moderate degrees of OSAS without any patient with severe OSAS. Another striking feature of our study is that $46 \%$ of patients with REM-related OSAS also had positional OSAS (20\% in the other group) with a significant intergroup difference. However, positional OSAS was not a significant factor for REM dependence in multiple regression analyses. $\mathrm{AHI}$ and minimum $\mathrm{O}_{2}$ saturation were independent predictors. For the definition of positional OSAS, the combined criteria of $\mathrm{AHI}_{\text {NON-SUPINE }}$ of $<5$ and $\mathrm{AHI}_{\text {SUPINE }}$ of $\geq 2 \times \mathrm{AHI}_{\text {NON-SUPINE }}$ were used (28). While sleeping in the supine position, the tongue and soft palate posteriorly deviate, which decrease pharyngeal cross-sectional area, leading to an increase in the frequency of respiratory events (29). As a combined effect of REM sleep and the supine position, preexisting OSAS will be further aggravated, and oxygen saturation will decrease. Therefore, when evaluating the PSG reports of patients with OSAS, AHI recorded at every stage of sleep and at all sleeping positions should be carefuly assessed.

Sleep architecture in patients with REM-related OSAS and non-REM-related groups demonstrates intergroup differences. Lakadamyalı et al. (24) observed comparable duration and percentage of hours slept in both the REM-related and non-related groups, while shorter NREM stage 1 and 2 sleep, but longer stage 3 sleep, were observed. In a separate study performed in an REM-related group, longer REM and deep sleep, but decreased NREM stage 1 sleep, were detected (3). In the REM-related group, we observed longer REM and NREM stage 3 sleep, but shorter stage 1 and 2 sleep.

REM sleep is characterized by a period of increased sympathetic activity and cardiovascular instability both in normal individuals and in those with OSAS. When episodes of obstructive apnea-hypopnea occurring during the REM stage are compared to respiratory events occurring during the NREM stage, the former episodes induce deeper hypoxemia and increased sympathetic activity. Therefore, REM-related respiratory events are associated with marked increases in cardiovascular risk (18). A striking finding is that in non-obese children with OSAS, REM-related OSAS is more frequently detected (19). In studies performed on children with OSAS, the development of morbidities as metabolic dysfunction, hypertension, vascular endothelial dysfunction, systemic inflammation, and increased oxidative stress have been demonstrated (30-33). Observations gathered from children display their importance in the definition of REM-related events in adults. The most striking outcome of our study is that comorbidities such as cerebrovascular disease, diabetes, hypertension, cardiovascular diseases, which are mostly seen in severe OSAS patients, were observed in a nearly equal number of patients in the REM-related group with mild-moderate OSAS and the non-REM-related group, which contained severe patients with OSAS. These results suggest that that REM-related OSAS is a different and important clinical entity. In a study by Rodríguez et al. (3), no difference was detected between REM-related and non-REM-related OSAS groups in cardiovascular risk factors and cardiovascular events. These outcomes demonstrate the importance of an early diagnosis and the treatment of patients with REM-related OSAS for the prevention of many significant systemic complications.

\section{CONCLUSION}

In light of the data obtained from our study, similarities between the REM-related OSAS and non-REM-related groups in mean age, BMI, and ESS and the lack of any intergroup difference between groups regarding the incidence rates of concomitant diseases such as as cardiovascular disease, diabetes, hypertension, and cardiovascular disease suggest that REM-related OSAS is a different clinical type of OSAS rather than a presentation of the beginning or early stages of classical OSAS. OSAS is a heterogenous syndrome including patients with different clinical features. Therefore, the determination of clinical types of OSAS and the early onset of appropriate therapy increase a patient's compliance to treatment and thus, treatment success rates. Besides, it has an importance in the prevention of many OSAS-related systemic complications.

Ethics Committee Approval: Ethics committee approval was received for this study from the ethics committee of Gaziosmanpaşa University.

Informed Consent: Written informed consent was obtained from all the patients in this study.

Peer-review: Externally peer-reviewed.

Author Contributions: Concept - H.I.K., A.K.; Design - H.I.K.; Supervision - H.I.K., A.K.; Resource - H.I.K.; Materials - H.I.K.; Data Collection and/or Processing - H.I.K., A.K.; Analysis and/or Interpretation - O.D.; Literature Review - H.I.K., A.K., O.D.; Writer - H.I.K., A.K., O.D.; Critical Review - A.K.

Conflict of Interest: No conflict of interest was declared by the authors.

Financial Disclosure: The authors declared that this study has received no financial support.

\section{REFERENCES}

1. McNicholas WT, Bonsigore MR. Management Committee of EU COST ACTION B26. Sleep apnoea as an independent risk factor for cardiovascular disease: current evidence basic and research priorities. Eur Respir J 2007; 29: 156-78. [CrossRef]

2. Javaheri S. Sleep Disordered Breathing Syndromes. In: Lee-Chiong TL, editor. Sleep, A Comprehensive Handbook. Canada, Wiley-Liss; 2006: 249-62.

3. Rodríguez FC, Palacín AF, Núñez NR, González AR. Clinical and Polysomnographic Features of Rapid Eye Movement-Specific Sleep-Disordered Breathing. Arch Bronconeumol 2009; 45: 330-4. [CrossRef] 
4. Fenik VB, Davies RO, Kubin L. REM sleep-like atonia of hypoglossal (XII) motoneurons is caused by loss of noradrenergic and serotonergic inputs. Am J Respir Crit Care Med 2005; 172: 1322-30. [CrossRef]

5. Conwell W, Patel B, Doeing D, Pamidi S, Knutson KL, Ghods F, et al. Prevalence, clinical features, and CPAP adherence in REM-related sleep-disordered breathing: a cross-sectional analysis of a large clinical population. Sleep Breath 2012; 16: 519-26. [CrossRef]

6. Koo BB, Dostal J, loachimescu O, Budur K. The effects of gender and age on REM-related sleep-disordered breathing. Sleep Breath 2008; 12: 25964. [CrossRef]

7. Johns MW. A new method for measuring daytime sleepiness: the Epworth Sleepiness Scale. Sleep 1991; 14: 540-5.

8. Sleep-Related Breathing Disorders in Adults: Recommendations for Syndrome Definition and Measurement Techniques in Clinical Research. The Report of an American Academy of Sleep Medicine Task Force. Sleep 1999; 22: 667-89.

9. Iber C, Ancoli-Israel S, Chesson A, Quan SF. The AASM manual for the scoring of sleep and associated events: rules, terminology, and technical specification, 2007, 1st ed. American Academy of Sleep Medicine, Westchester.

10. Kass JE, Akers SM, Bartter TC, Pratter MR. Rapid-eye-movement-specific sleep-disordered breathing: a possible cause of excessive daytime sleepiness. Am J Respir Crit Care Med 1996; 154: 167-9. [CrossRef]

11. Haba-Rubio J, Janssens JP, Rochat T, Sforza E. Rapid eye movementrelated disordered breathing: clinical and polysomnographic features. Chest 2005; 128: 3350-7. [CrossRef]

12. Resta O, Carpanano GE, Lacedonia D, Di Gioia G, Giliberti T, Stefano A, et al. Gender difference in sleep profile of severely obese patients with obstructive sleep apnea. Respir Med 2005; 99: 91-6. [CrossRef]

13. Koo BB, Patel SR, Strohl K, Hoffstein V. Rapid eye movement-related sleep-disordered breathing: influence of age and gender. Chest 2008; 134 : 1156-61. [CrossRef]

14. Su CS, Liu KT, Panjapornpon K, Andrews N, Foldvary-Schaefer N. Functional outcomes in patients with REM-related obstructive sleep apnea treated with positive airway pressure therapy. J Clin Sleep Med 2012; 8: 243-7. [CrossRef]

15. Oksenberg A, Arons E, Nasser K, Vander T, Radwan H. REM-related obstructive sleep apnea: the effect of body position. J Clin Sleep Med 2010; 6: 343-8.

16. Gillman $A$, Roebuck T, Ho S, BraakEV, Naughton MT. Comparison of supine-only and REM-only obstructive sleep apnoea. Sleep Medicine 2012; 13: 875-8. [CrossRef]

17. Boujaoude ZC, Abouzgheib WB, Aboujaoude RN, Dagher HN, Pratter MR, Akers SM, et al. The frequency of REM specific OSA. Chest 2003; 124: 74 S.

18. Goh DY, Galster P, Marcus CL. Sleep architecture and respiratory disturbances in children with obstructive sleep apnea. Am J Respir Crit Care Med 2000; 162: 682-6. [CrossRef]
19. O'Connor C, Thornley KS, Hanly PJ. Gender differences in the polysomnographic features of obstructive sleep apnea. Am J Respir Crit Care Med 2000; 161: 1465-72. [CrossRef]

20. Somers VK, Dyken ME, Mark AL, Abboud FM. Sympathetic-nerve activity during sleep in normal subjects. N Engl J Med 1993; 328: 303-7. [CrossRef]

21. Somers VK, Dyken ME, Clary MP, Abboud FM. Sympathetic neural mechanisms in obstructive sleep apnea. J Clin Invest 1995; 96: 1897-904. [CrossRef]

22. Findley $\mathrm{L}$, Wilhoit SC, Suratt PM. Apnea duration and hypoxemia during REM sleep in patients with obstructive sleep apnea. Chest 1985; 87: 432-6. [CrossRef]

23. Mokhlesi B, Punjabi NM. "REM-related" Obstructive Sleep Apnea: An Epiphenomenon or a Clinically Important Entity? Sleep 2012; 35: 5-7. [CrossRef]

24. Lakadamyalı H, Güven SF, Çiftçi B, Eyüboğlu FÖ. Rapid eye movement related obstructive sleep apnea syndrome: antropometric and polysomnographic findings. Tuberk Toraks 2012; 60: 13-9. [CrossRef]

25. Haba-Rubio J, Janssens JP, Rochat T, Sforza E. Rapid eye movement-related disordered breathing: clinical and polysomnographic features. Chest 2005; 128: 3350-7. [CrossRef]

26. Romero-Corral A, Caples SM, Lopez-Jimenez F, Somers VK. Interactions between obesity and obstructive sleep apnea: implications for treatment. Chest 2010; 137: 711-9. [CrossRef]

27. Oksenberg A, Arons E, Nasser K, Vander T, Radwan H. REM-related Obstructive Sleep Apnea: The Effect of Body Position. J Clin Sleep Med 2010; 6: 343-8.

28. Permut I, Diaz-Abad M, Chatila W, Crocetti J, Gaughan JP, D'Alonzo GE, et al. Comparison of positional therapy to CPAP in patients with positional obstructive sleep apnea. J Clin Sleep Med 2010; 6: 238-43.

29. Schwab RJ, Kuna ST, Remmers JE. Anatomy and Physiology of Upper Airway Obstruction. In: Kryger MH, Roth T, Dement WC, editors. Principles and Practise of Sleep Medicine, 4rd edn. Philadelphia, WB Saunders; 2005: 983-1000. [CrossRef]

30. Redline S, Storfer-Isser A, Rosen CL, Johnson NL, Kirchner HL, Emancipator J, et al. Association between metabolic syndrome and sleep-disordered breathing in adolescents. Am J Respir Crit Care Med 2007; 176: 401-8. [CrossRef]

31. Gozal D, Kheirandish-Gozal L, Serpero LD, Sans CO, Dayyat E. Obstructive sleep apnea and endothelial function in school-aged nonobese children: effect of adenotonsillectomy. Circulation 2007; 116: 2307-14. [CrossRef]

32. Kheirandish-Gozal L, Bhattacharjee R, Kim J, Clair HB, Gozal D. Endothelial progenitor cells and vascular dysfunction in children with obstructive sleep apnea. Am J Respir Crit Care Med 2010; 182: 92-7. [CrossRef]

33. Bhattacharjee R, Kheirandish-Gozal L, Pillar G, Gozal D. Cardiovascular complications of obstructive sleep apnea syndrome: evidence from children. Prog Cardiovasc Dis 2009; 51: 416-33. [CrossRef] 